\title{
A Landsat-based Assessment of Mobile Bay Land Use and Land Cover Change from 1974 to 2008
}

\author{
Joseph Spruce, ${ }^{1}$ Jean Ellis, ${ }^{2}$ James Smoot, ${ }^{1}$ Roberta Swann, ${ }^{3}$ William Graham ${ }^{4}$ \\ 1 Science Systems \& Applications, Inc., Stennis Space Center, MS 39529 \\ 2University of South Carolina, Columbia, SC 29208 \\ ${ }^{3}$ Mobile Bay National Estuary Program, Mobile, AL 36615 \\ ${ }^{4}$ NASA Code PA30, Stennis Space Center, MS 39529
}

The Mobile Bay region has experienced noteworthy land use and land cover (LULC) change in the latter half of the 20th century. Accompanying this change has been urban expansion and a reduction of rural land uses. Much of this LULC change has reportedly occurred since the landfall of Hurricane Frederic in 1979. The Mobile Bay region provides great economic and ecologic benefits to the Nation, including important coastal habitat for a broad diversity of fisheries and wildlife. Regional urbanization threatens the estuary's water quality and aquatic-habitat dependent biota, including commercial fisheries and avian wildlife. Coastal conservation and urban land use planners require additional information on historical LULC change to support coastal habitat restoration and resiliency management efforts.

This presentation discusses results of a Gulf of Mexico Application Pilot project that was conducted in 2008 to quantify and assess LULC change from 1974 to 2008 . This project was led by NASA Stennis Space Center and involved multiple Gulf of Mexico Alliance (GOMA) partners, including the Mobile Bay National Estuary Program (NEP), the U.S. Army Corps of Engineers, the National Oceanic and Atmospheric Administration’s (NOAA’s) National Coastal Data Development Center (NCDDC), and the NOAA Coastal Services Center.

Nine Landsat images were employed to compute LULC products because of their availability and suitability for the application. The project also used Landsat-based national LULC products, including coastal LULC products from NOAA's Coastal Change \& Analysis Program (C-CAP), available at 5-year intervals since 1995. Our study was initiated in part because C-CAP LULC products were not available to assess the region’s urbanization prior to 1995 and subsequent to post Hurricane Katrina in 2006.

This project assessed LULC change across the 34-year time frame and at decadal and middecadal scales. The study area included the majority of Mobile and Baldwin counties that encompass Mobile Bay. In doing so, each date of Landsat data was classified using an end-user defined modified

Participation in this work by Science Systems and Applications, Inc., was supported by NASA under Task Order NNS04AB54T at the John C. Stennis Space Center, Mississippi 
Anderson level 1 classification scheme. LULC classifications were refined using a decision rule approach in conjunction with available C-CAP products. Individual dates of LULC classifications were validated by image interpretation of stratified random locations on raw Landsat color composite imagery in combination with higher resolution remote sensing and in-situ reference data.

The results indicate that during the 34-year study period, urban areas increased from 96,688 to 150,227 acres, representing a 55.37\% increase, or 1.63\% per annum. Most of the identified urban expansion results from conversion of rural forest and agriculture to urban cover types. Final LULC mapping and metadata products were produced for the entire study area as well as watersheds of concern within the study area. Final project products, including LULC trend information, were incorporated into the Mobile Bay NEP State of the Bay report. Products and metadata were transferred to NOAA NCDDC to allow free online accessibility and use by GOMA partners and by the public.

Abstract for submittal to OCEANS 2009 MTS/IEEE, Biloxi, Mississippi, USA

Participation in this work by Science Systems and Applications, Inc., was supported by NASA under Task Order NNS04AB54T at the John C. Stennis Space Center, Mississippi 


\title{
A Landsat-based Assessment of Mobile Bay Land Use and Land Cover Change from 1974 to 2008
}

\author{
Joseph Spruce, ${ }^{1}$ Jean Ellis, ${ }^{2}$ James Smoot, ${ }^{1}$ Roberta Swann, ${ }^{3}$ William Graham ${ }^{4}$ \\ ${ }^{1}$ Science Systems \& Applications, Inc., Stennis Space Center, MS 39525 \\ ${ }^{2}$ University of South Carolina, Columbia, SC 29208 \\ ${ }^{3}$ Mobile Bay National Estuary Program, Mobile, AL 36615 \\ ${ }^{4}$ NASA Code PA30, Stennis Space Center, MS 39529
}

\begin{abstract}
This paper discusses results of a Gulf of Mexico Application Pilot project conducted in 2008 to quantify and assess land use land cover (LULC) change from 1974 to 2008. Led by NASA Stennis Space Center, this project involved multiple Gulf of Mexico Alliance (GOMA) partners, including the Mobile Bay National Estuary Program (NEP), the U.S. Army Corps of Engineers, the National Oceanic and Atmospheric Administration's (NOAA's) National Coastal Data Development Center (NCDDC), and the NOAA Coastal Services Center. The Mobile Bay region provides great economic and ecologic benefits to the Nation, including important coastal habitat for a broad diversity of fisheries and wildlife. The Mobile Bay region has experienced considerable LULC change since the latter half of the 20th century. Accompanying this change has been urban expansion and a reduction of rural land uses. Much of this LULC change (largely urbanization) has reportedly occurred since the landfall of Hurricane Frederic in $1979 . \quad$ Regional urbanization threatens the estuary's water quality and aquatic-habitat dependent biota, including commercial fisheries and avian wildlife. Coastal conservation and urban land use planners require additional information on historical LULC change to support coastal habitat restoration and resiliency management efforts. This project quantified and assessed LULC change across the 34-year time frame and at decadal and mid-decadal scales. Nine Landsat images were employed to compute LULC products because of their availability and suitability for the application. The project also used Landsat-based national LULC products, including coastal LULC products from NOAA's Coastal Change \& Analysis Program (C-CAP), available at 5-year intervals since 1995. Our study was initiated in part because C-CAP LULC products were not available to assess the region's urbanization prior to 1995 and subsequent to postHurricane Katrina in 2006.

The study area included the majority of Mobile and Baldwin counties that encompass Mobile Bay. Each date of Landsat data was classified using an end-user defined modified Anderson level 1 classification scheme. LULC classifications were refined using a decision rule approach in conjunction with available C-CAP products. Individual dates of LULC classifications were validated by image interpretation of stratified random locations on raw Landsat color composite imagery in combination with higher resolution remote sensing and in situ reference data. Overall classification accuracies for five separate single-date products ranged from $83 \%$ to $89 \%$. The results of the LULC change analysis indicate that during the 34-year study period, urban areas increased from 96,688 to 150,227 acres, representing a $55.37 \%$ increase, or $1.63 \%$ per annum. Most of the identified urban expansion regarded the conversion of rural forest and agriculture to urban cover types. Final LULC mapping and metadata products were produced for the entire study area as well as for multiple watersheds of concern within the study area. The final project products, including LULC trend information, were incorporated into the Mobile Bay NEP State of the Bay report. Products and metadata were also transferred to NOAA NCDDC to allow free online accessibility and use by GOMA partners and by the public.
\end{abstract}

\section{INTRODUCTION}

This paper discusses an effort to employ Landsat time series data to quantify and assess land use land cover (LULC) change in the Mobile Bay region over the past 35 years. Such products are needed to aid planning efforts for sustainable land use, coastal conservation, and coastal restoration planning in the region.

\section{A. Project Rationale and Objectives}

The Mobile Bay region provides great economic and ecologic benefits to the Nation, including important coastal habitat for a broad diversity of fisheries and wildlife. It has also experienced considerable LULC change since the latter half of the 20th century. Accompanying this change has been urban expansion and a reduction of rural land uses. Much of this LULC change (largely urbanization) has reportedly occurred since the landfall of Hurricane Frederic in 1979. Mobile Bay was designated as an estuary of national significance in 1996 [1]. Regional urbanization threatens the estuary's water quality and aquatic-habitat dependent biota, as well as commercial fisheries and avian wildlife. Approximately 50\% of Alabama's wetlands were lost by the mid-1980s [2]. Coastal conservation and urban land use planners in this region require additional geospatial information on historical LULC change to support coastal habitat restoration and resiliency management efforts [3, 4].

In response, a Gulf of Mexico Application (GOMA) Pilot project was conducted in 2008 to quantify and assess LULC change from 1974 to 2008. Led by NASA Stennis Space Center, this project involved multiple GOMA partners, including the Mobile

Participation in this research by Science Systems and Applications, Inc., was supported by NASA at the John C. Stennis Space Center, Mississippi, under Task Order NNS04AB54T. 
Bay National Estuary Program (MBNEP), the U.S. Army Corps of Engineers, the National Oceanic and Atmospheric Administration's (NOAA's) National Coastal Data Development Center (NCDDC), and the NOAA Coastal Services Center. The study area includes the majority of Mobile and Baldwin counties that encompass Mobile Bay (Fig. 1). The primary research objective was for NASA SSC to compute Landsat-based historic and current LULC change detection products for aiding MBNEP coastal resource planning, outreach, and education decision support needs. This research objective included four main technical objectives that applied Landsat time series data to quantify and assess 1 ) regional LULC change from 1974 to 2008; 2) regional change due to urban expansion at decadal scales; 3) LULC change for specific watersheds of concern from 1974 to 2008; and 4) watershed-scale change due to urban expansion at decadal scales. This paper focuses on technical objectives one and two. Information on watershed scale analyses (technical objectives three and four) are discussed in the project's final report [5].

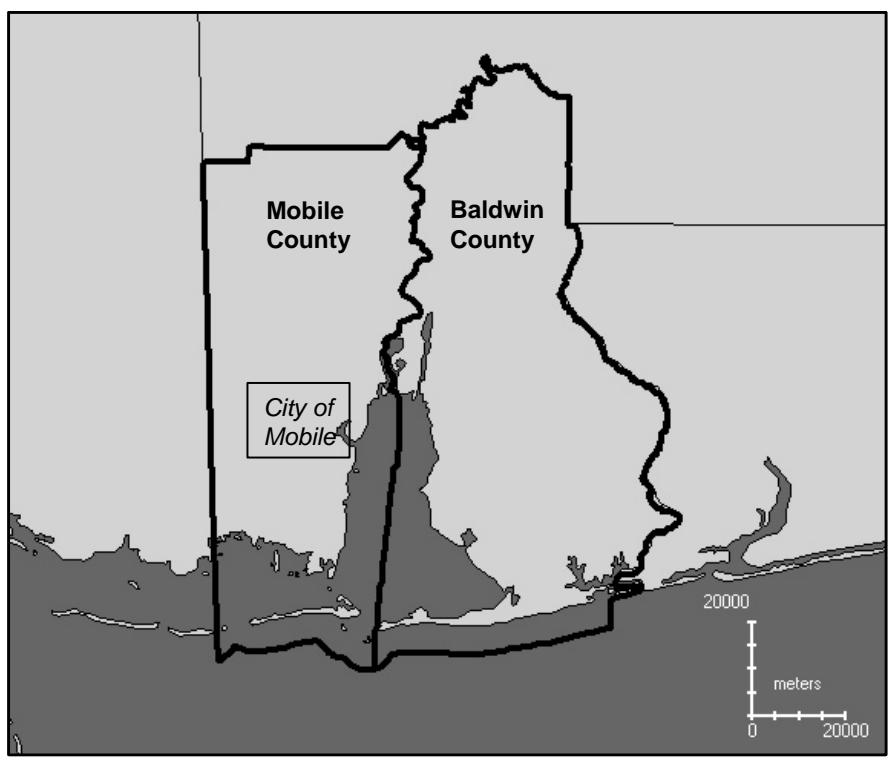

Fig. 1 Location map for study area.

\section{B. Previous Relevant Coastal LULC Efforts Based on Landsat Data}

Much of the previous coastal LULC work with Landsat data pertains to products from the Coastal Change and Analysis Program (C-CAP) administered by NOAA's Coastal Services Center [6]. The C-CAP has been producing LULC products at 5year intervals since the mid-1990s. In addition, C-CAP produced products in 2006 for the region impacted by Hurricane Katrina, which includes Mobile Bay. Most of these products have been produced using Landsat TM or ETM data in conjunction with the Cowardin wetland [7] and the Anderson LULC [8] classification schemes. The available C-CAP products have much higher classification specificity than can be needed for basic LULC change detection analyses. Coastal zone managers without GIS skills and computer equipment are not necessarily able to recode C-CAP products into more generalized, end-user customized LULC schemes. C-CAP products have a high overall accuracy specification of $85 \%$ or better [9].

Landsat data have been used on multiple occasions to quantify and assess LULC change in Gulf of Mexico coastal areas, including (going west to east) coastal south-central Louisiana [10], Mermentau River Basin of Louisiana [11], Barataria Basin of Louisiana [12], Coastal Mississippi [13], Grand Bay of Mississippi [14], Pensacola Bay of Florida [15], and Tampa Bay of Florida [16]. Similar applications have been done in other coastal regions of the country, such as for Chesapeake Bay [17]. In contrast, a literature review revealed a few previous studies of Mobile Bay LULC change, although none were identified as using multiple dates of Landsat data throughout the Landsat era. To the best of the authors' knowledge, none of these efforts have been published in peer-reviewed journals.

Change detection products from C-CAP are produced through image classification of LULC for a given year followed by postclassification change detection of two different years. The LULC classification for each surveyed year is computed through use of multiple seasons of Landsat data in conjunction with elevation, impervious cover, and tree canopy cover products. This process is similar to that used in the National Land Cover Database (NLCD) of 2001, although at a higher level of classification specificity for the wetland categories. Given the cloud cover frequency of the region, it is difficult to acquire multiple seasons of cloud-free Landsat data for a given year. Fortunately, there are image processing and GIS techniques that can enable useful coastal LULC products from single-date Landsat data, although doing so usually requires adoption of a more general classification scheme compared to C-CAP products. C-CAP products are not available for dates prior to the mid-1990s.

Other relevant LULC classification products are also available for the study area, including NLCD and National Wetland Inventory (NWI) products. The latter has been enhanced for the Mobile Bay region to include more upland and urban categories than is common to standard NWI products. However, in going from the 1950s to 2002, these products were produced from multiple types (e.g., panchromatic and color infrared) and multiple scales of aerial photography. Consequently, even with C-CAP, NLCD, and NWI products available, additional Landsat change detection analysis spanning the Landsat era was desirable and therefore pursued for this project.

\section{METHODS}

The necessary LULC change detection products were computed from Landsat time series data from 1974 to 2008. Single dates of largely cloud-free Landsat data were acquired for 9 different years including 11/12/1974, 10/26/1979, 09/06/1984, 02/22/1988, 09/26/1991, 01/27/1996, 03/05/2001, 03/24/2005, and 03/16/2008. Each date of Landsat data was georeferenced to a common database: the orthorectified Landsat Thematic Mapper scene from 09/26/1991. The latter was an orthorectified product acquired 
through NASA’s Scientific Data Purchase program. Each Landsat dataset was imported into ERDAS IMAGINE ${ }^{\circledR}$ software. All acquired Landsat data was 30 meter resolution, except for three dates of Landsat MSS data (1974, 1979, and 1984) sampled at 60 meter resolution. The 30 meter Landsat data were processed so that each dataset contained a 6-channel data stack of the visible, near infrared, and shortwave infrared reflectance bands. The Landsat MSS data were processed into a 4-channel data stack consisting of visible and near infrared bands.

Each date of Landsat data was classified using a decision rule model in conjunction with unsupervised classification techniques. In doing so, an end-user defined LULC classification scheme was utilized, containing upland herbaceous, upland forest, nonwoody wetland, woody wetland, open water, and urban categories, which is equivalent to a modified Anderson Level I classification system [7]. An ISODATA unsupervised classification routine resident to ERDAS IMAGINE software was used to cluster each Landsat scene into spectral cluster classes. Each cluster class was interpreted using reference data (e.g., aerial photography of comparable vintage to the Landsat date) to identify each represented LULC type.

A decision rule classifier deployed as a series of spatial models in ERDAS was then used to compute a refined classification based on a weighting scheme that involved the use of C-CAP products. On a per-cluster class basis, a value of one was assigned to the attribute column for each LULC class when the cluster included that LULC category. A value of zero was assigned to the attribute column for each LULC class when the cluster class did not pertain to a given LULC class. Spatial models were constructed to produce binary masks of each targeted LULC class. C-CAP products were used to reduce classification confusion of certain targeted classes; in particular, urban, woody wetlands, and non-woody wetlands. C-CAP LULC data products for 1996, 2001, and 2005 (pre-Hurricane Katrina) were recoded using our 7-class Landsat classification system. Maximum extent images of urban, woody wetlands, and non-woody wetland LULC categories were computed from the union of the 1996, 2001, and 2005 extent of each applicable category. These masks were not mutually exclusive and additional editing was performed using a maximum value compositing approach to compute a discrete, thematic, wall-to-wall refined classification.

For each sampled Landsat date, a spatial model was implemented to merge the individual classifications of LULC classes into a wall-to-wall product to complete the primary LULC classification process. This model used a maximum value compositing technique in which certain LULC categories were weighted higher to reduce classification confusion. If needed, additional classification refinement was completed to reduce visible classification error. Such editing usually was done by reclassification of an identified problematic class, generally using raw data masking and cluster busting techniques described by [18].

Accuracy assessments were performed for several dates of LULC classifications. In doing so, locations on each date of classification were randomly sampled using a stratified random sampling approach in which the drawn sample per class was proportionally allocated according to class frequency. The randomly sampled locations were viewed on available digital reference data that included ground reference data, high resolution orthorectified aerial photography, high resolution multispectral and panchromatic satellite or aerial data displays, digital elevation model data (for wetland class assessment), and NWI wetland cover type data (for wetland class assessment). Landsat false color composites RGBs were also used as a reference in LULC map accuracy assessment when higher resolution imagery were not available.

Change detection analysis consisted over post-classification GIS-based overlay analysis for each 2-date comparison of interest to the end-user, including comparisons of LULC change across the entire time series and at decadal time frames. These comparisons were then simplified to further assess phenomenon of urbanization. Landsat scenes were cropped to include only Mobile and Baldwin counties for regional scale analysis.

\section{RESULtS}

Below are examples of results obtained in the project, including sample results for assessments of regional LULC change and regional urbanization change.

\section{A. Regional LULC Change}

Comparisons of LULC classification products provided visual indication of where LULC change occurred within the study area. As suspected, for the Landsat time series, much of the LULC change appeared to occur prior to the C-CAP era. This change is primarily due to urbanization. The rural areas that fringe the City of Mobile metro area also showed change attributed to plantation forestry practices. The change between 1974 and 2008 is depicted in Fig. 2. The most prominent visual indication of the urban expansion is around the City of Mobile and along the eastern shore of Mobile Bay. The northeast portion of the study area shows that some upland forest has changed to the upland herbaceous land cover type. This change is probably transitional in nature, due to forest harvesting cycles. The results of the LULC change analysis indicate that during the 34-year study period, urban areas increased from 96,688 acres to 150,227 acres, representing a 55.37\% increase, or 1.63\% per annum.

A graphical comparison of percent coverage of each LULC category for each date of classification is given in Fig. 3. Urban cover increases throughout the time series with an approximate 30\% increase in this type between 1974 and 1979 . The urban cover frequency increases to about $60 \%$ when considering the entire time series. There is noteworthy fluctuation among the upland herbaceous and upland forest landscapes. These data suggest a cyclical land swapping between upland herbaceous and 
upland forest landscape, however, this research was unable to make this conclusion definitely. The non-woody wetlands decreased over time $(-6.4 \%$, or $\sim 2400$ acres), while the woody wetlands slightly increased $(+3.4 \%$, or $\sim 6500$ acres).

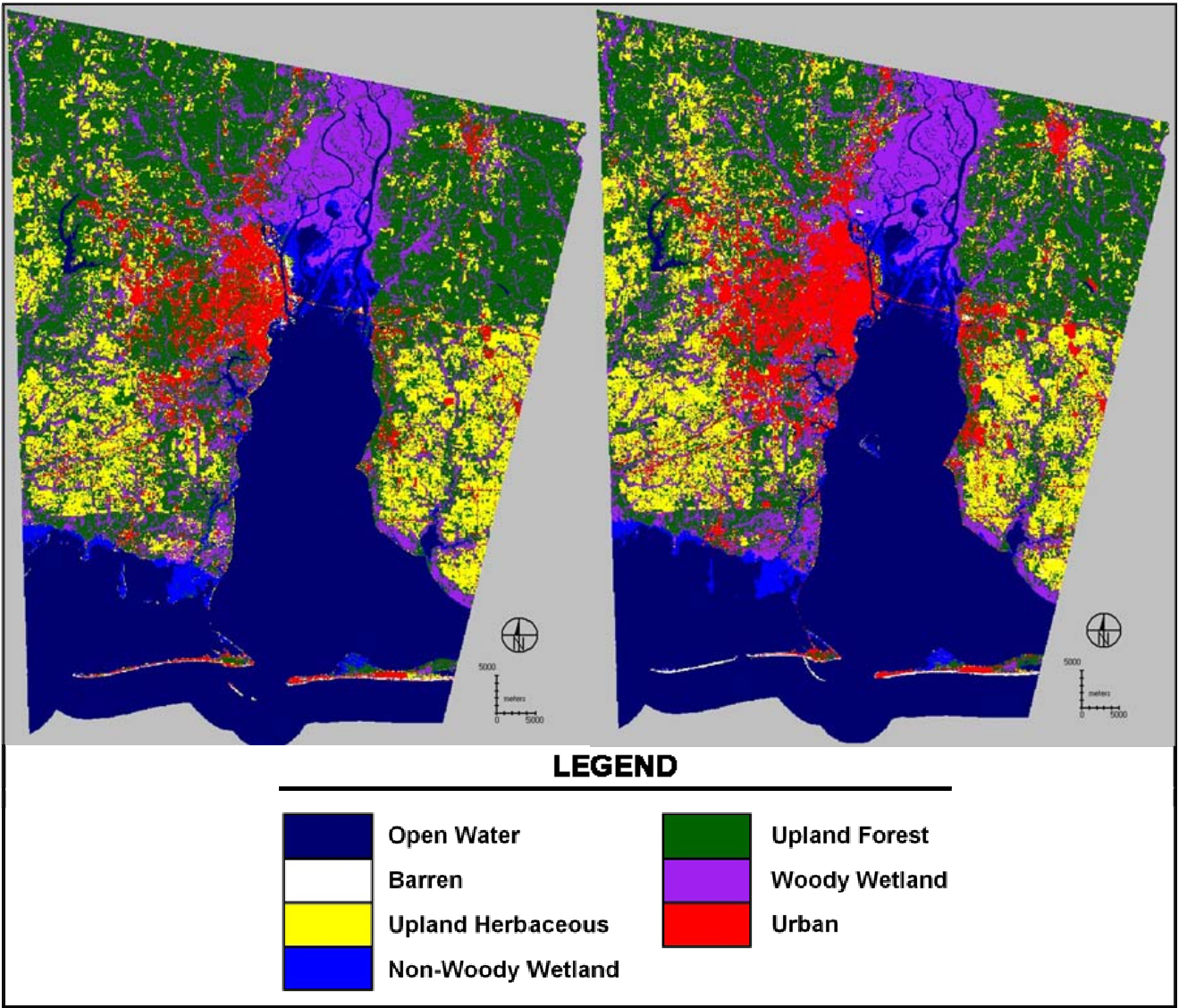

Fig. 2 Landsat-derived land-use and land-cover data product for 1974 (left) and 2008 (right) showing surveyed area within Mobile and Baldwin counties (graphic previously published in [20].

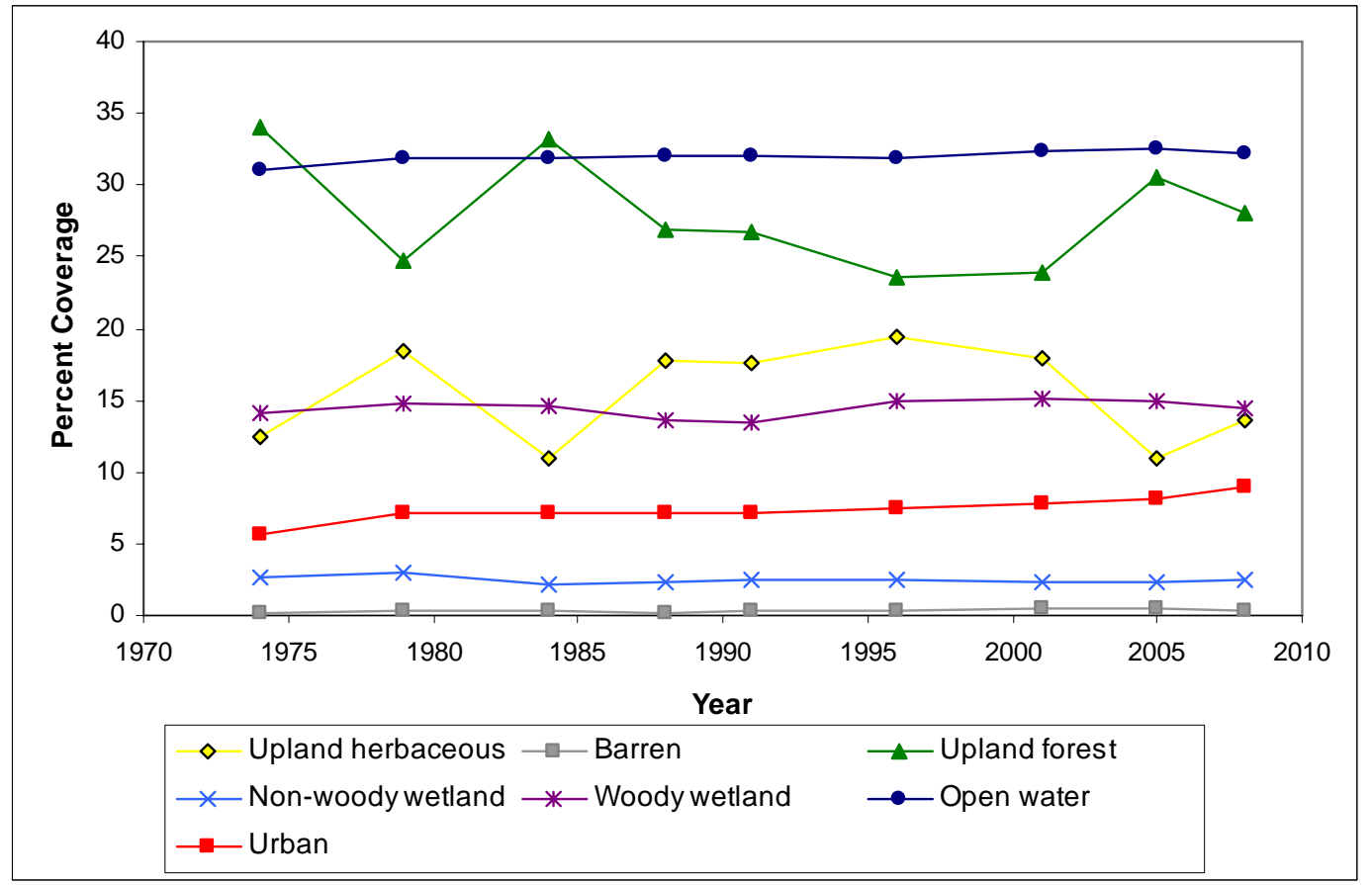

Fig. 3 Percent coverage change relative to 1974 for each land-use and land-cover class (except barren) for Mobile and Baldwin counties. Tabular data show the Landsat-derived geospatial statistics for each land-use and land-cover class in acres. Barren was excluded from the figure because this land cover type comprises a small percent of the total coverage $(<0.5 \%$, is often transitional in nature, and its small acreage changes are not readily observed in relation to the other LULC categories. 
The results of the LULC classification accuracy assessment are given in Table 1. The overall accuracy (i.e., agreement with reference data) ranged from 83.13\% (2005) to 89.33\% (1979), and the Kappa values for these classifications ranged from 0.78 (2005) to 0.87 (1979). The sampling intensity for these assessments ranged from 150 (1979) to 190 (2008) total random samples per classification. In all cases, the overall accuracy exceeded $80 \%$ and the Kappa either approached or exceeded 0.8 (on a scale of 0 to 1 ). The use of Landsat MSS data (1979, at $60 \mathrm{~m}$, rather than post 1984 at $30 \mathrm{~m}$ ) did not seem to lower the accuracy. However, only one MSS product was assessed for accuracy, and additional accuracy assessment is needed.

\section{B. Regional Urbanization Change}

Urbanization visualization products illustrate urban expansion at the decadal scale throughout the Landsat time series (Fig. 4). Much of the apparent expansion occurs on the western flank of the City of Mobile, although some is also evident on the eastern settled portion of Mobile Bay in Baldwin County. Most of the urbanization occurs in the 1974-1984 time frame, which precedes the time during which C-CAP products are available. The urban growth compared to the underlying

Table 1 Overall accuracy of 1979, 1996, 2001, 2005, and 2005 land-use land-cover classifications compared to available reference data.

\begin{tabular}{|l|ccc|}
\hline Year & Overall Accuracy (\%) & Overall Kappa & Total Samples \\
\hline 1979 & 89.33 & 0.87 & 150 \\
1996 & 86.88 & 0.84 & 160 \\
2001 & 88.00 & 0.85 & 150 \\
2005 & 83.13 & 0.78 & 160 \\
2008 & 89.06 & 0.86 & 192 \\
\hline
\end{tabular}
elevation model in Fig. 4 show the relationship of urbanization to the low lying land and to the waterways in these areas. In some cases, development occurs in close proximity to waterways, representing a potential increased risk for water pollution issues.

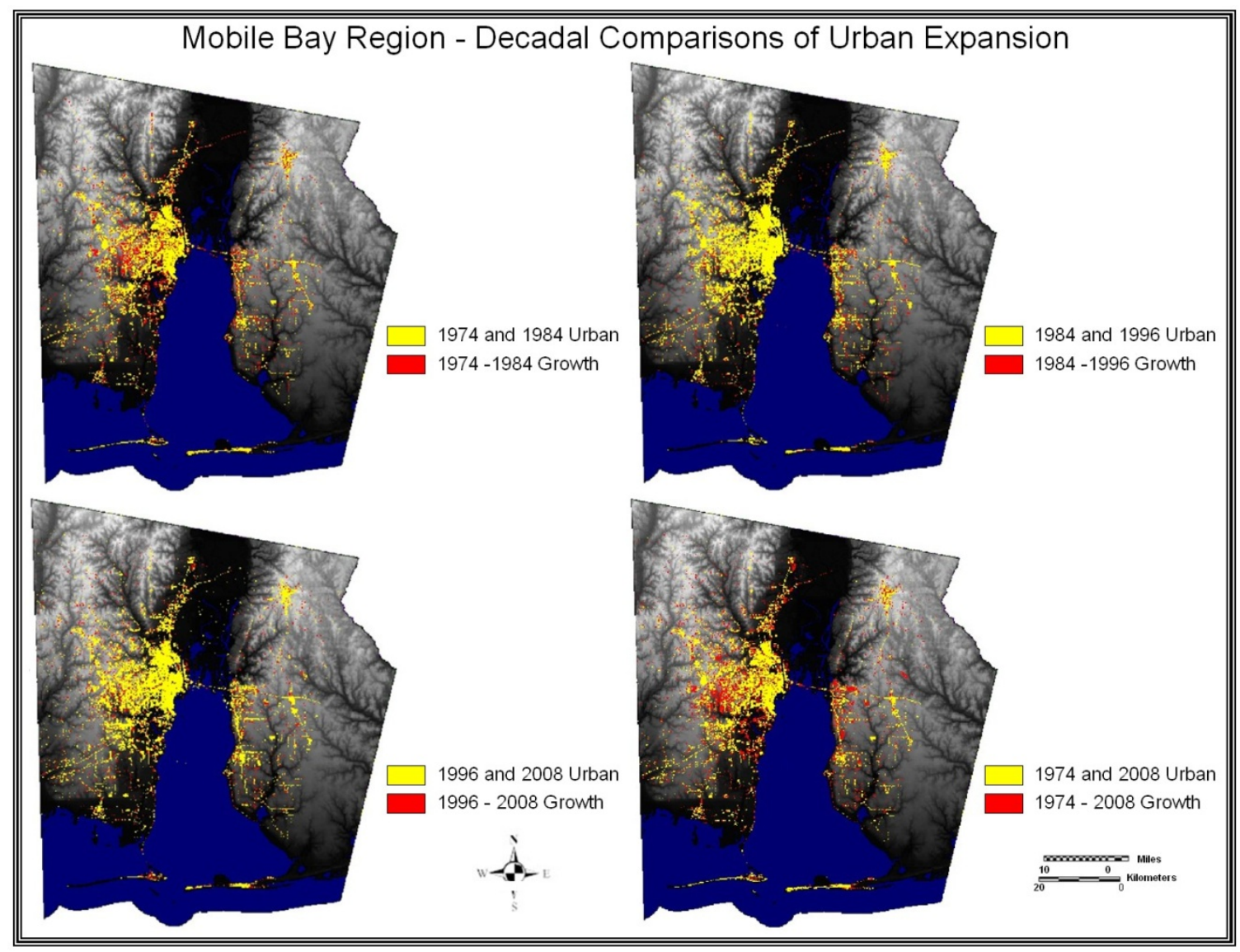

Fig. 4 Decadal-scale of urban expansion for Mobile and Baldwin counties. The area shown is common to all four dates used in the analysis, done in an effort to standardize change comparisons across all dates. 


\section{CONCLUSIONS}

Multitemporal Landsat data were useful for quantification and assessment of LULC change in the Mobile Bay region over the surveyed 34-year time frame. This was the case for regional- as well as watershed-scale analysis. The LULC classification technique employed in this study enabled products with high apparent classification accuracy (i.e., agreement) compared to available reference data for all 5 dates of classifications examined for relative accuracy. The LULC products here have recently been utilized to aid the Mobile Bay NEP in efforts to promote and aid coastal conservation and habitat restoration. In particular, the final project products, including LULC trend information, were incorporated into the Mobile Bay NEP State of the Bay report and Comprehensive Conservation and Management Plan (CCMP) work plan [3, 4]. To benefit GOMA partners, the public, and academic institutions, products and metadata are available for free download from a NOAA NCDDC FTP site [19]. Additional information on this work is given in the final report for the project [5].

\section{ACKNOWLEDGMENT}

NASA’s Applied Science and Technology Project Office supported J. Ellis. T. McPherson assisted with project management.

\section{REFERENCES}

[1] U.S. Environmental Protection Agency, Oceans and Watersheds: A Watershed's Decade, EPA 840-R-00-002, Office of Wetlands, Oceans, and Watersheds, 45 p., 2001.

[2] W.J. Mitsch and J.G. Gosselink, Wetlands, 2nd edition, New York, NY: Van Norstrand Reinhold, 722 pp., 1993.

[3] Mobile Bay National Estuary Program, State of Mobile Bay: A Status Report on Alabama's Coastline from the Delta to Our Coastal Waters, 48 pp., 2008.

[4] Mobile Bay National Estuary Program, Mobile Bay National Estuary Program CCMP Work Plan Year 14 Fiscal Year 2010,82 pp., 2009.

[5] J. Ellis, J. Spruce, R. Swann, and J. Smoot, Land Use and Land-Cover Change from 1974-2008 around Mobile, AL, Final Report, December 2008 (executive summary online at http://www2.nos.noaa.gov/gomex/habitatid/eia nasa_lulc.pdf accessed August 21, 2009).

[6] J.E. Dobson et al., NOAA Coastal Change Analysis Program (C-CAP): Guidance for Regional Implementation, NOAA Technical Report NMFS 123, U.S. Department of Commerce, Seattle, Washington, 1995.

[7] L.M. Cowardin, V. Carter, F.C. Golet, and E.T. LaRoe, Classification of Wetlands and Deepwater Habitats of the United States. U.S. Department of the Interior, Fish and Wildlife Service, Washington, D.C., 131 pp., 1979.

[8] J.R. Anderson, E.E. Hardy, J.T. Roach, and R.E. Witmer, A Land Use and Land Cover Classification System for Use with Remote Sensor Data, Geological Survey Professional Paper 964, 41 pp., 1976.

[9] National Oceanic and Atmospheric Association, Coastal Change Analysis Program Regional Land Cover, 2009, (http://www.csc.noaa.gov/digitalcoast/data/ccapregional/index.html accessed August 24, 2009).

[10] E.W. Ramsey and S.C. Laine, "Comparison of Landsat Thematic Mapper and high resolution photography to identify change in complex coastal wetlands," . Journal of Coastal Research, vol. 13, pp. 281-292, 1997.

[11] E.W. Ramsey, G.A. Nelson, and S.K. Sapkota, “Coastal change analysis program implemented in Louisiana,” Journal of Coastal Research, vol. 17, pp. 53$71,2001$.

[12] S.A.C. Nelson, P.A. Soranno, and J. Qi, "Land-over change in Upper Barataria Basin Estuary, Louisiana, 1972-1992: Increases in wetland area," Environmental Management, vol. 29, pp. 716-727, 2002.

[13] C.G. O'Hara, J.S. King, J.H. Cartwright, and R.L. King, "Multitemporal land use and land cover classification of urbanized areas within sensitive coastal environments: Urban remote sensing by satellite," IEEE Transactions on Geoscience and Remote Sensing, vol. 41, pp. 2005-2014, 2003.

[14] K.W. Hilbert, “Land cover change within the Grant Bay National Estuarine Research Reserve: 1974-2001,” Journal of Coastal Research, vol. 22, pp. 15521557,2006

[15] X. Yang and Z. Liu, Z., "Using satellite imagery and GIS for land-use and land-cover change mapping in an estuarine watershed,” International Journal of Remote Sensing, vol. 26, pp. 5275-5296, 2005.

[16] G. Xian and M. Crane, "Assessment of urban growth in the Tampa Bay watershed using remote sensing data," Remote Sensing of Environment, vol. 97, pp. 203-215, 2005.

[17] P. Jantz, S.J. Goetz, and C.A. Jantz, “Urbanization and the loss of resource lands within the Chesapeake Bay watershed,” Environmental Management, vol. 36, pp. 808-825, 2005.

[18] J.R. Jensen, E.W. Ramsey, H.E. Mackey, E.J. Christensen, and R.R. Sharitz, "Inland wetland change detection using aircraft MSS data,” Photogrammetric Engineering and Remote Sensing, vol. 53, pp. 521-529, 1987.

[19] National Oceanic and Atmospheric Association, 2009, NOAA NCDDC FTP site, ftp://ftp.ncddc.noaa.gov/pub/Mobile_Bay_LULC/ (accessed August 24, 2009).

[20] A.H. Peek et al, "Stennis Space Center uses NASA remote sensing assets to address coastal Gulf of Mexico issues,” Photogrammetric Engineering \& Remote Sensing, vol. 74, pp. 1449-1453, 2008. 


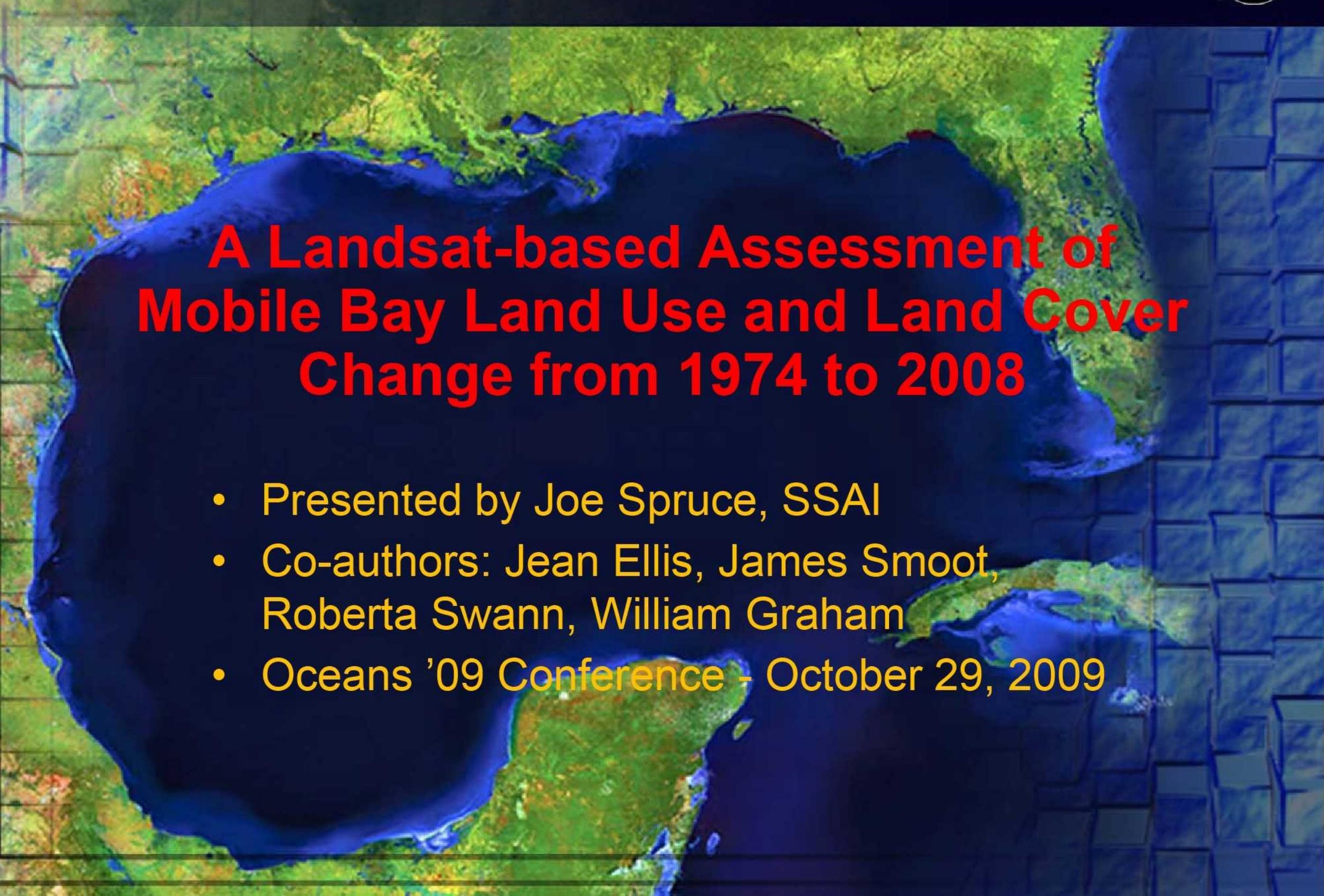




\section{Discussion Items}

Stennis Space Center

- Project Background

- Technical Objectives

- Product Development Method

- Example Results

- Discussion

- Final Remarks 


\section{Project Background}

- Goal - Assess Mobile Bay Land Use Land Cover (LULC) change to aid coastal habitat conservation and restoration

- Partners - Mobile Bay National Estuary Program (end-user) and Gulf of Mexico Alliance (GOMA) collaboration network

- Rationale - Project fueled by concerns about urbanization, water quality, habitat conservation, and LULC change occurring over the last 35 years

- Scope

- Produced regional LULC classifications for 9 dates of Landsat data from 1974 to 2008

- Computed LULC change detection products across multiple intervals of the 1974-2008 time frame

- Posted final LULC products and metadata on a National Oceanic and Atmospheric Administration (NOAA) data portal for use in the GOMA community 


\section{Technical Objectives}

1. Assess regional LULC change from 1974 to 2008

2. Assess regional urban LULC change at decadal time scales

3. Assess LULC change for specific watersheds of concern from 1974 to 2008

4. Assess urban LULC change for specific watersheds at decadal time scales

(Note - this presentation will pertain primarily to technical objectives 1 and 2) 


\section{Study Area Location}

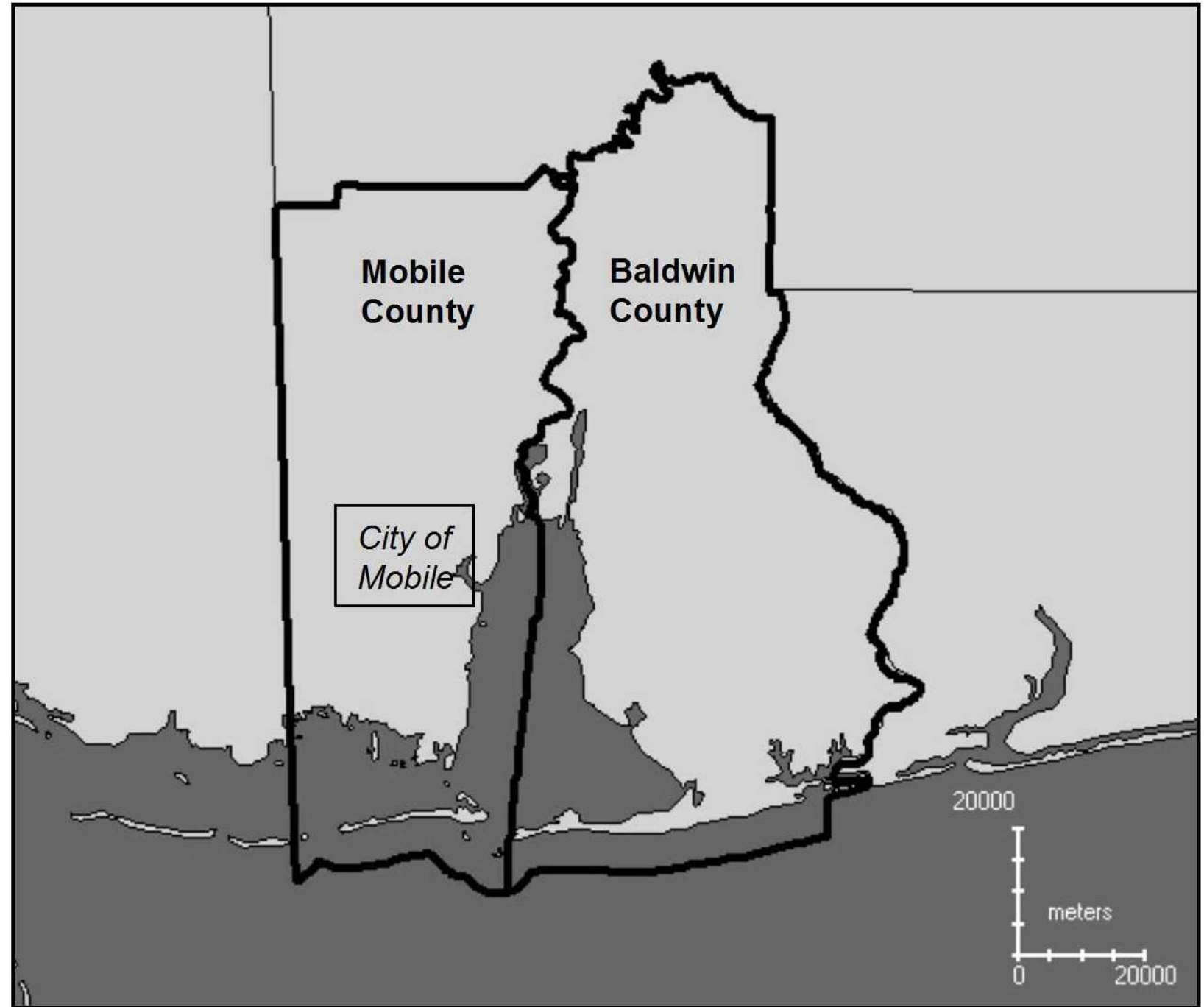




\section{Product Development Method}

- Acquired Landsat data for 9 dates from 1974 to 2008

- Employed general LULC scheme (7 classes)

- Includes open water, barren, upland herbaceous, non-woody wetland, upland forest, woody wetlands, and urban

- Computed LULC classifications for each Landsat dataset

- Assessed accuracy of LULC products for multiple dates

- Compared changes in total acreage of LULC types across the 1974-2008 time series

- Produced map compositions, charts, and summary tables depicting LULC change across the region and for watersheds of concern within the region 


\section{Mobile Bay LULC 1974 versus 2008}

1974 LULC Product

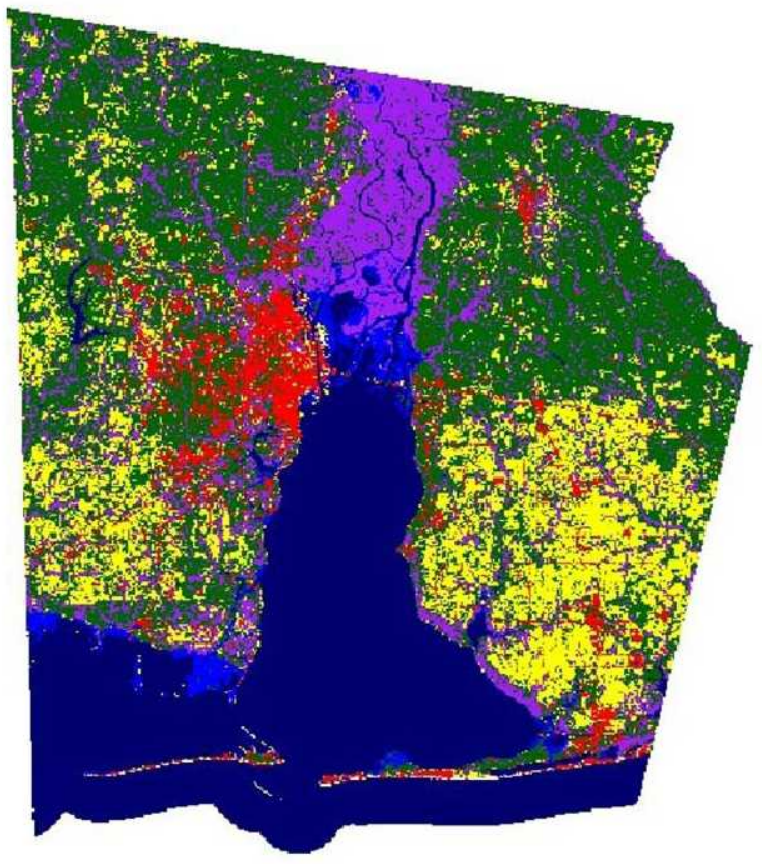

Landsat Multispectral Scanner Data Acquired: 11/12/1974

\section{LULC Product}

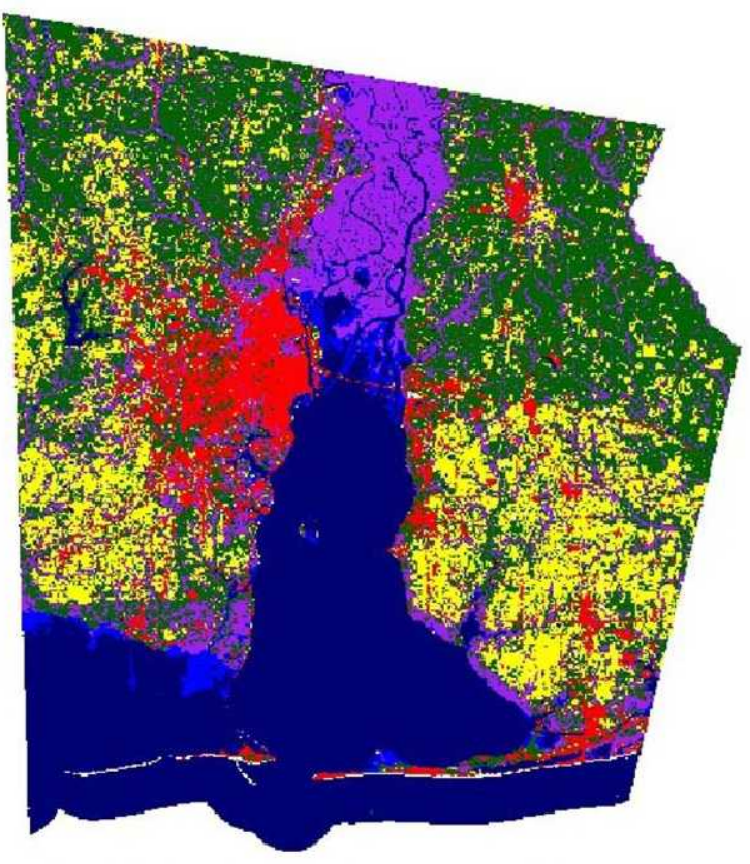

Landsat Thematic Mapper Data Acquired : 03/16/2008

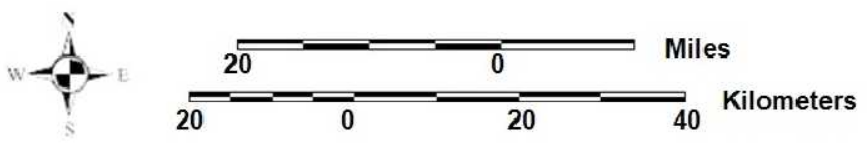

Landsat-based LULC products indicated a 58.9\% increase in urban areas from 1974 to 2008.

Much of this urbanization involved conversion of upland forest to urban cover types. 


\section{Trends in Mobile Bay LULC for 9 Dates from 1974 to 2008}

Stennis Space Center

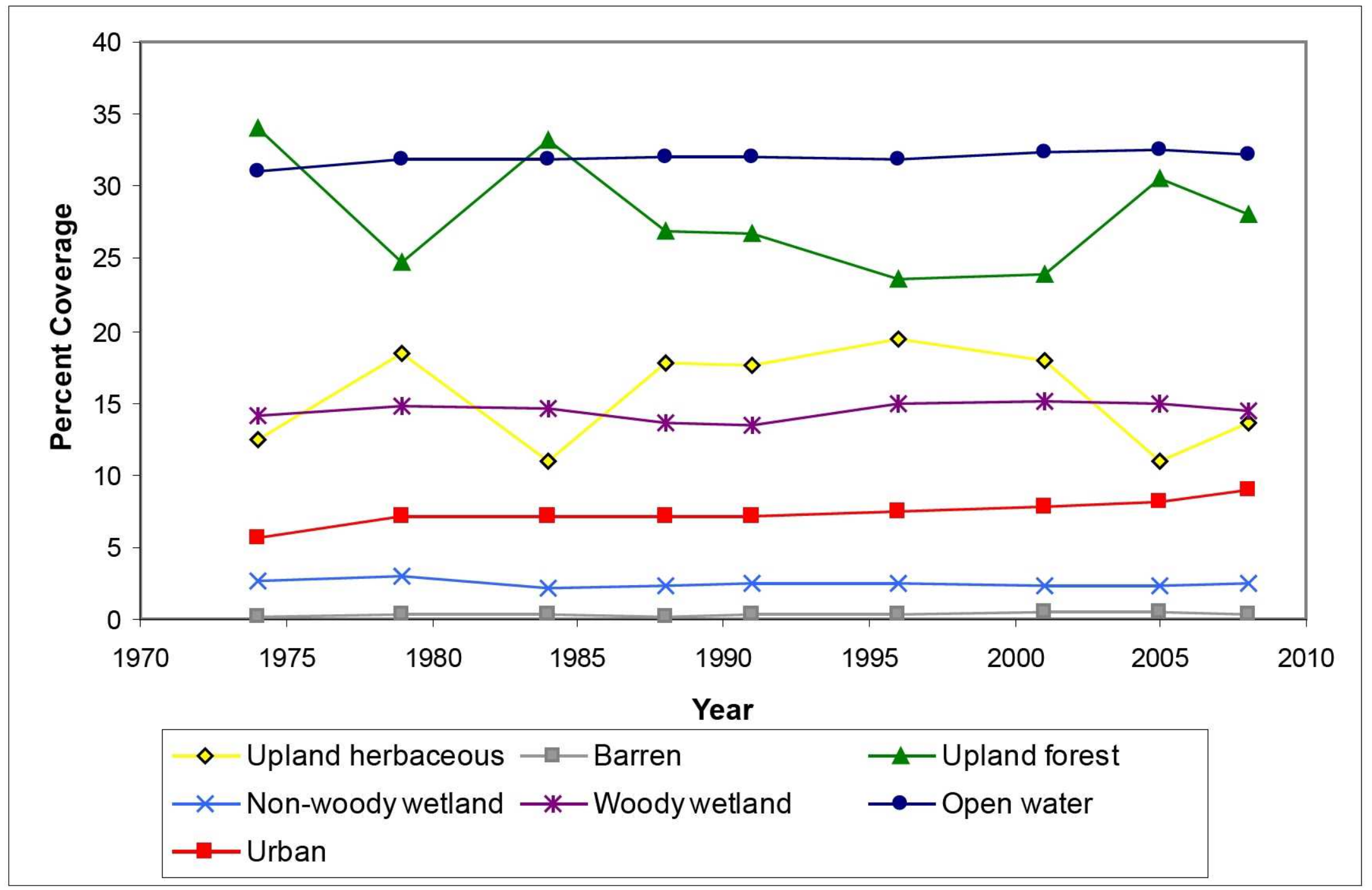




\section{Views of Urban Expansion within Northern Mobile Bay Area}

Stennis Space Center
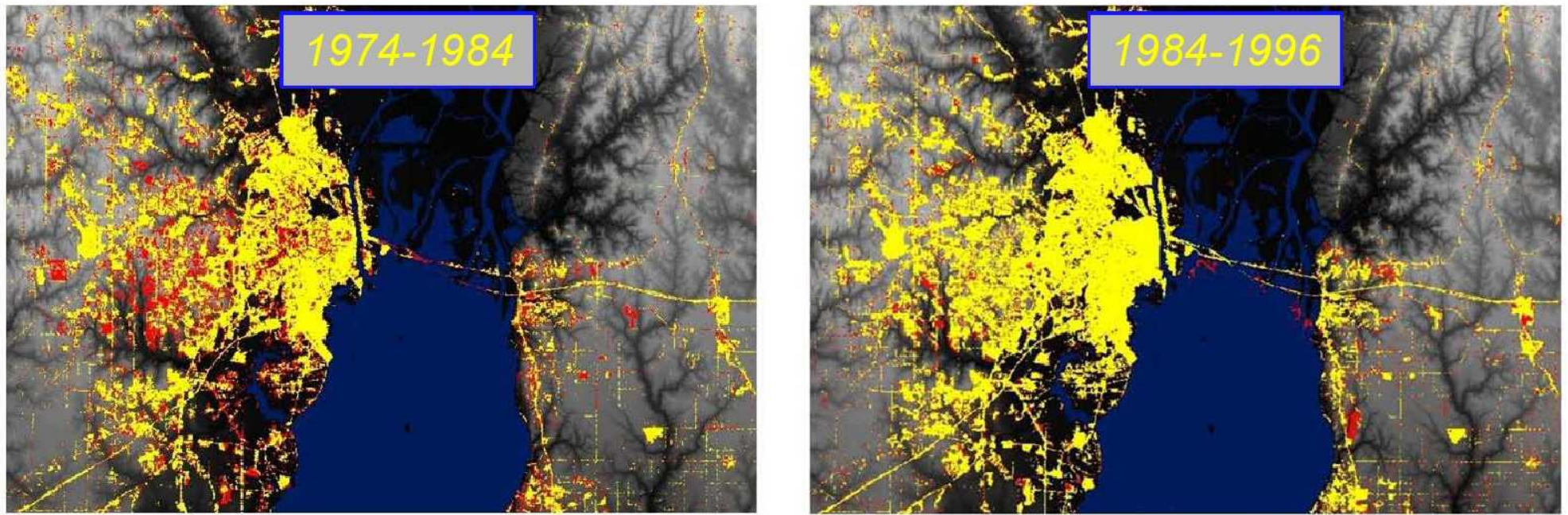

$\square 1974$ and 1984 Urban

1974 -1984 Growth

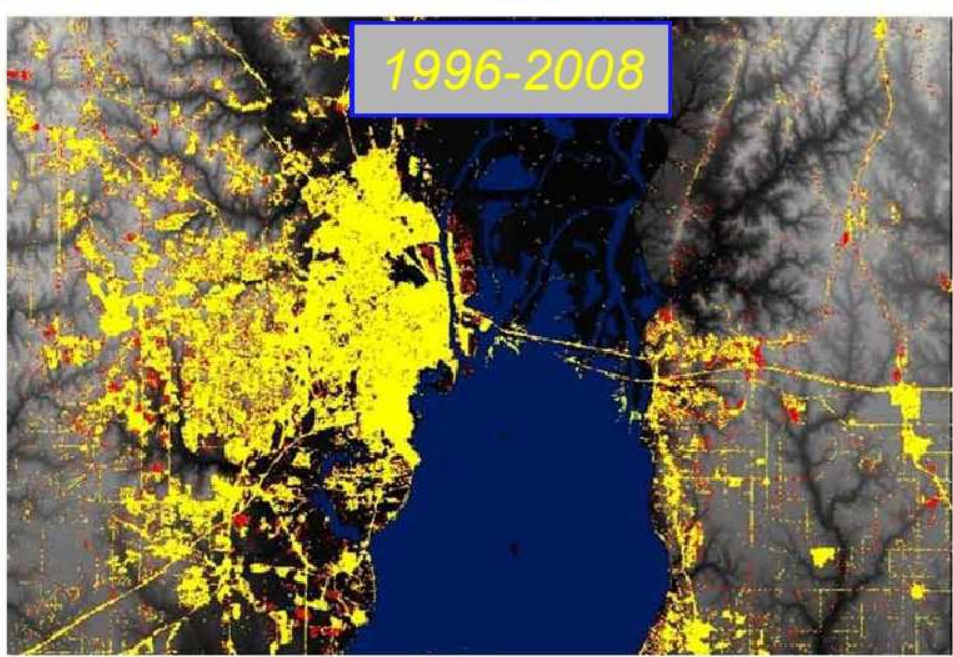

$\square 1984$ and 1996 Urban $\square 1984-1996$ Growth

$\square 1996$ and 2008 Urban $\infty$

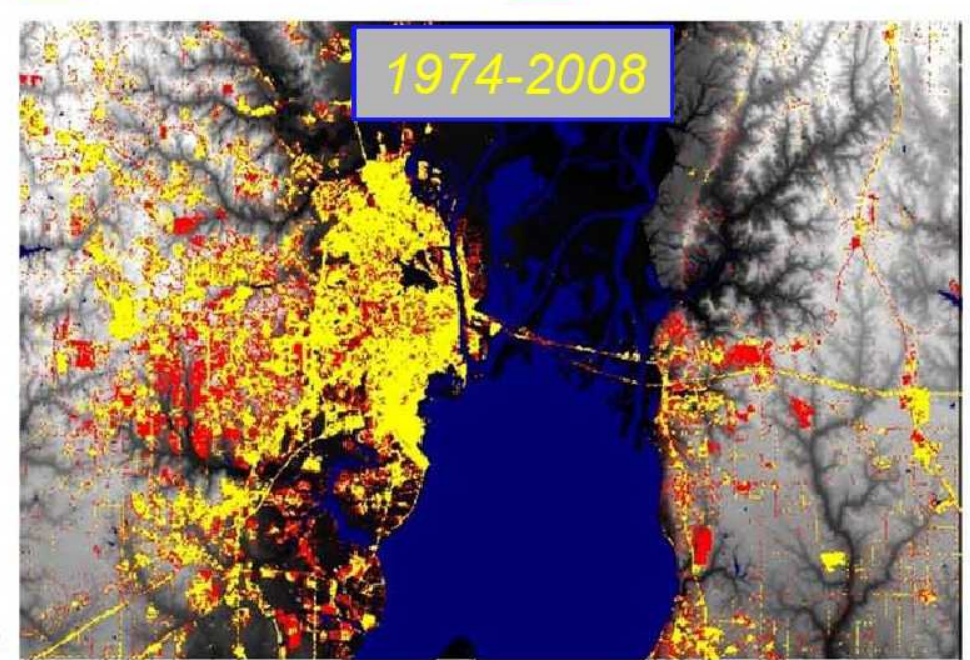

its

1974 and 2008 Urban $=-1-0$ Miles 


\section{Results of LULC Classification Accuracy Assessment}

Overall accuracy (i.e., agreement) of 1979, 1996, 2001, 2005, and 2008 LULC classifications compared to available reference data.

\begin{tabular}{|c|c|c|c|}
\hline Year & Overall Accuracy (\%) & Overall Kappa & Total Samples \\
\hline 1979 & 89.33 & 0.87 & 150 \\
\hline 1996 & 86.88 & 0.84 & 160 \\
\hline 2001 & 88.00 & 0.85 & 150 \\
\hline 2005 & 83.13 & 0.78 & 160 \\
\hline 2008 & 89.06 & 0.86 & 192 \\
\hline
\end{tabular}




\section{Discussion}

- Project yielded new geospatial information on LULC change from 1974 to 2008, including change that took place prior to earliest National Land Cover Database (NLCD) and Coastal Change Analysis Program (C-CAP) products

- For the 1974-2008 era, much of Mobile Bay's regional urbanization occurred prior to the 1990s (i.e., before available NLCD and C-CAP LULC products)

- Project results aided coastal habitat conservation and restoration work of the Mobile Bay National Estuary Program

- Results aided Mobile Bay State of the Bay Report and Comprehensive Conservation and Management Plan

- The project enabled useful LULC analyses to be performed at regional and watershed scales 


\section{Final Remarks}

- A final report on this project was submitted to NASA. The executive summary of this report is online at: http://www2.nos.noaa.gov/gomex/habitatid/eia nasa lulc.pdf.

- Results from this project are being submitted for publication in the Journal of Estuaries and Coasts

- Final data products and metadata from the initial project can be obtained online at: ftp://ftp.ncddc.noaa.gov/pub/Mobile Bay LULC/

- This work has led to a follow-on, NASA-funded study that will further assess LULC change to promote and aid coastal conservation and restoration. Dr. Jean Ellis, University of South Carolina, will lead this new 2-year project. 


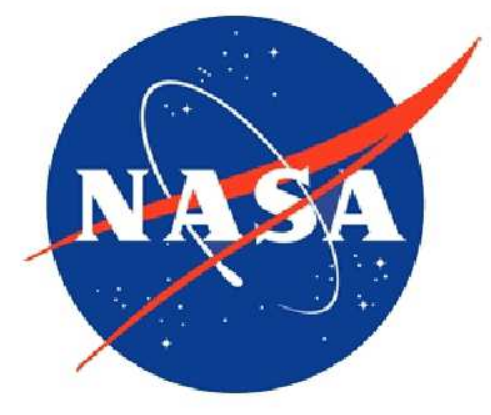

Participation in this work by Science Systems and Applications, Inc., was supported by NASA at the John C. Stennis Space Center, Mississippi, under Task Order NNS04AB54T. 